\title{
O ensino de estratégias de leitura mediado por sequências didáticas
}

\author{
La enseñanza de estrategias de lectura mediada por \\ secuencias didácticas
}

\section{Reading strategies instruction through pedagogical sequences}

\author{
Márcia Andréa Almeida de Oliveira', Renata Maria de Souza²
}

\begin{abstract}
RESUMO: Neste artigo, apresentamos uma reflexão sobre o ensino de estratégias de leitura, durante a realização de três sequências didáticas orientadas por gênero em turmas do $9^{\circ}$ ano do Ensino Fundamental II. Para realizar a pesquisa, apoiamo-nos nos estudos sobre estratégias de leitura e modelização didática, os quais nos guiaram na construção de modelos e sequências didáticas e na análise dos dados construídos ao longo de 32 horas-aula. Como procedimento metodológico, recorremos às pesquisas qualitativa e documental, a fim de alcançar o nosso objetivo de pesquisa, a saber: demonstrar se houve o ensino de estratégias de leitura aos estudantes e de que maneira tais estratégias foram ensinadas. Os resultados da pesquisa mostraram que em determinados momentos as estagiárias levaram os alunos a desenvolver estratégias de leitura, mas em outros as instruções apresentadas e os procedimentos utilizados na realização das atividades mostraram-se insuficientes para que eles, primeiro, entendessem as estratégias de leitura como uma forma de melhorar a compreensão leitora e, segundo, aprendessem a utilizá-las. A análise revelou que as estagiárias sabiam em que consistia cada estratégia prevista nas sequências didáticas, mas tiveram dificuldades em ensiná-las, o que nos leva a pensar que os cursos de formação de professores precisam focar mais em instruções de leitura.
\end{abstract}

PALAVRAS-CHAVE: Ensino de leitura. Estratégia de leitura. Sequência didática.

\footnotetext{
${ }^{1}$ Pós-doutoranda em Harvard Graduate School of Education. Doutora em Linguística Aplicada pela Universidade de Campinas. Mestra em Letras: Linguística e Teoria Literária pela Universidade Federal do Pará.

2 Formada em Letras-Língua Portuguesa pela Universidade Federal do Pará, ex-bolsista pródoutor (PIBIC) na área de Ensino - aprendizagem
} 
RESUMO: En este artículo, presentamos una reflexión sobre la enseñanza de estrategias de lectura durante la aplicación de tres secuencias didácticas orientadas por género en grupos del noveno curso de la Enseñanza Fundamental II. Para realizar esta investigación, nos apoyamos en estudios sobre estrategias de lectura y modelización didáctica, que sirvieron de guía en la construcción de modelos y secuencias didácticas, y en el análisis de los datos obtenidos a lo largo de 32 horas de clase. Como procedimiento metodológico, recurrimos al modelo cualitativo y documental con el fin de alcanzar el objetivo de la investigación: demostrar si a los alumnos se les enseñaron estrategias de lectura y de qué manera se hizo. Los resultados de la investigación mostraron que en determinados momentos las estudiantes en prácticas consiguieron que los alumnos desarrollasen estrategias de lectura, pero en otros las instrucciones presentadas y los procedimientos utilizados en la aplicación de las actividades se mostraron insuficientes para que los alumnos, primero, entendiesen las estrategias de lectura como una forma de mejorar la comprensión lectora y, segundo, aprendiesen a utilizarlas. El análisis reveló que las estudiantes en prácticas sabían en qué consistía cada estrategia prevista en las secuencias didácticas, pero tuvieron dificultades al enseñarlas, lo que nos lleva a pensar que los cursos de formación de profesores necesitan prestar más atención a las instrucciones de lectura.

PALABRAS CLAVE: Enseñanza de lectura. Estrategia de lectura Secuencia didáctica.

ABSTRACT: In this article, we present a reflection on reading strategies teaching. We analyzed 32 classroom hours, which was accomplished in classes of the 9th grade. We supported the research on reading strategies and didactic modeling. This theoretical framework guided us through the construction of pedagogical models and sequences, as well as through the analysis of the data. We developed qualitative and documentary research to achieve our primary goal, that is: demonstrate if the reading strategies instruction was implemented to students and how these strategies were taught. The process of examining the data revealed that trainees, who participated in this study, led the students to develop reading strategies. Nevertheless, we noticed that the instructions performed to explain activities were insufficient. We realized that 9th graders were not able to understand reading strategies as a way to improve text comprehension. They also didn't learn how to use it for making meaning from the text. Besides, we verified that trainees knew each preview strategy that was suggested from the didactic sequences. Meanwhile, they had difficulties in teaching them. We think it may be avoided if Portuguese teacher training focuses more on comprehension instructions.

KEYWORDS: Reading instruction. Reading strategy. Pedagogical sequence.

\section{Introdução}

Ler é uma forma de descobrir o mundo e de transformar minimamente a realidade. Aprende-se a ler para aprender, para se informar, para se posicionar, para fruir textos literários etc. Por isso, é de suma importância que se estimule 
desde os primeiros anos da vida infantil o contato com a leitura. Segundo a Base Nacional Comum Curricular - BNCC, a leitura é fundamental para pesquisa de trabalhos escolares, sustentar opinião, envolver-se em prática de leitura literária etc. (BRASIL, 2017).

Considerando os resultados do Sistema de Avaliação da Educação Básica - Saeb (INEP, 2017), que mostram que apenas 52,92\% dos alunos cursando o $9^{\circ}$ ano alcançam o nível 3 de 9, decidimos realizar oficinas de leitura junto a alunos desse ano escolar de três escolas públicas (municipais e estaduais) da cidade de Belém. Para tanto, com base nos pressupostos teóricos sobre gênero (BAKHTIN, 1997; SCHNEUWLY; DOLZ, 2004), sequência didática (NOVERRAZ; SCHNEWULY; DOLZ, 2004), modelo didático (DE PIETRO; SCHNEWULY, 2006) e estratégia de leitura (KOCH; ELIAS, 2014; MENEGASSI, 2010; SOLÉ, 1998), organizamos sequências didáticas de leitura estruturadas em torno de três gêneros textuais: artigo de opinião, artigo enciclopédico e conto de terror. A escolha desses gêneros se deu em razão de considerarmos o primeiro importante para "pesquisa e embasamento de trabalhos escolares e acadêmicos", o segundo, para "conhecimento, discussão e debate sobre temas sociais relevantes" e 0 terceiro, para "fruição estética de textos e obras literárias" (BRASIL, 2017, p. 69).

Para a realização do nosso trabalho, valemo-nos de diferentes tipos de pesquisa: qualitativa e documental (PRODANOV; FREITAS, 2013), a fim de produzir, descrever e analisar os dados construídos, de modo a alcançar nosso objetivo geral: demonstrar se houve o ensino de estratégias de leitura aos estudantes e de que maneira tais estratégias foram ensinadas. Com base nesse objetivo, buscamos responder às nossas perguntas de pesquisa: (i) De que forma a sequência didática planejada possibilitou ensinar sistematicamente estratégias de leitura? e (ii) Como os conhecimentos relacionadas a estratégias foram mobilizados pelas estagiárias no desenvolvimento da sequência didática?

Com vistas a direcionar as discussões aqui propostas, discorremos inicialmente sobre leitura, ressaltando a relevância de se ensinar estratégias; depois, abordamos o gênero textual e o processo de modelização didática; em seguida, descrevemos a metodologia utilizada na pesquisa; e por fim, 
sistematizamos e analisamos o corpus considerando as duas perguntas de pesquisa a que nos propusemos responder neste artigo.

\section{As Estratégias de Leitura e seu Papel no Desenvolvimento da Compreensão Leitora}

Fundamentados em Antunes (2003), Solé (1998) e Koch e Elias (2014), concebemos a leitura sob uma visão interativa, isto é, autor e leitor interagem por meio do texto. Nessa perspectiva, o ato de ler requer um leitor ativo que participa da construção do sentido, que não lê todos os textos com o mesmo objetivo e da mesma forma. A leitura é assim compreendida como uma "atividade interativa altamente complexa de produção de sentidos" e um processo "sociocognitivo-interacional".

Numa visão também interativa, Antunes (2003, p. 66) define o processo de leitura como "[...] parte da interação verbal escrita, enquanto implica a participação cooperativa do leitor na interpretação e na reconstrução do sentido e das intenções pretendidas pelo autor". Nesse processo, o leitor deve considerar os elementos linguísticos, pois são essas marcas, utilizadas pelo autor, que lhe possibilitam reconstruir o sentido do texto, embora não sejam as únicas mobilizadas para a compreensão e a interpretação do texto.

No processo de leitura, o leitor pode acionar diferentes estratégias que lhe permitem construir sentidos com base nos textos lidos. Solé (1998) considera que as estratégias de leitura são importantes e precisam ser ensinadas. Contudo, não devemos tratá-las como receitas infalíveis. A autora explica que

[...] a compreensão do que se lê é produto de três condições: da clareza e coerência do conteúdo dos textos, do grau em que o conhecimento prévio do leitor seja relevante para o conteúdo do texto e das estratégias que o leitor utiliza para intensificar a compreensão e a lembrança do que lê. (SOLÉ, 1998, p. 71). 
Isso evidencia que as estratégias não são as únicas envolvidas no processamento do texto, no entanto é uma parte importante a ser considerada se o propósito é desenvolver habilidades em leitura.

A autora defende o ensino de estratégias durante as três etapas do processo de leitura, isto é: antes, durante e depois. Antes da leitura, é necessário que o leitor tenha um objetivo para sua realização, porque isso vai determinar a forma como o indivíduo vai interagir com o texto. Segundo Koch e Elias (2014, p. 19), são "[...] os objetivos do leitor que nortearão o modo de leitura em mais tempo ou menos tempo; com mais atenção ou com menos atenção; com maior interação ou com menor interação.". Solé (1998) elenca alguns objetivos para a prática de leitura, como: ler para obter uma informação de caráter geral; ler para aprender; ler para revisar o próprio texto; ler por prazer; ler para comunicar um texto a um auditório; ler para praticar a leitura em voz alta e ler para verificar o que se compreendeu.

Sobre o ensino de estratégias a serem acionadas antes da leitura, Solé (1998) sugere, por exemplo, que o professor peça aos alunos que levantem hipóteses com base no título e exponham o conhecimento que possuem sobre 0 assunto do texto. Tais procedimentos os ajudam a se tornar leitores ativos, que sabem por que leem e que compreendem a importância dos conhecimentos prévios no ato de ler.

Quanto às estratégias mobilizadas durante a leitura, a autora apresenta como sugestão a atividade de leitura compartilhada, que consiste no seguinte:

O professor e os alunos devem ler um texto, ou um trecho de um texto, em silêncio (embora também possa haver leitura em voz alta). Depois da leitura, o professor conduz os alunos através das quatro estratégias básicas. Primeiro se encarrega de fazer um resumo do que foi lido para o grupo e solicita sua concordância. Depois pode pedir explicações ou esclarecimentos sobre determinadas dúvidas do texto. Mais tarde formula uma ou algumas perguntas às crianças, cuja resposta torna a leitura necessária. Depois desta atividade, estabelece suas previsões sobre o que ainda não foi lido, reiniciando-se deste modo o ciclo (ler, resumir, solicitar esclarecimentos, prever), desta vez a cargo de outro "responsável" ou moderador. (SOLÉ, 1998, p. 71). 
Por meio desse tipo de atividade, é possível focar as estratégias de formulação de previsões sobre o texto, a formulação de perguntas sobre o que foi lido, o esclarecimento de possíveis dúvidas e a recapitulação das ideias do texto.

No tocante às estratégias depois da leitura, é válido, entre outras coisas, trabalhar a compreensão que os alunos têm sobre a ideia principal do texto e como eles podem reconhecê-la, bem como criar meios para que eles desenvolvam habilidades de resumir textos e de responder perguntas a eles relacionadas.

Ainda com base nos estudos sobre compreensão leitora, um bom leitor é aquele que usa estratégias.

\footnotetext{
Desde o começo, eles [bons leitores] têm objetivos claros na mente para sua leitura. Eles constantemente avaliam se o texto, e a leitura dele, está atingindo seus objetivos. [...]

Quando eles leem, bons leitores frequentemente predizem o que está por vir.

Eles leem seletivamente, continuamente tomando decisões sobre sua leitura - o que ler cuidadosamente, o que ler rapidamente, o que não ler, o que reler etc.

Bons leitores constroem, revisam, e questionam o significado que eles atribuem quando leem. (DUKE; PEARSON, 2002, p. 205, grifo dos autores, tradução nossa).
}

Tais características de um bom leitor reforçam a necessidade de ajudar os alunos a adquirir as estratégias de leitura, com vistas a desenvolver sua compreensão leitora. Por isso, decidimos elaborar sequências didáticas que permitissem o ensino consciente de algumas dessas estratégias.

\section{O Ensino e a Aprendizagem de Gêneros Textuais}

Nesta seção, discorremos sobre o que são gêneros textuais e em que consiste o processo de modelização, destacando o que são modelo didático e sequência didática, conforme o pressuposto teórico aqui assumido. 


\section{Gêneros textuais}

Bakhtin (1997) define gêneros do discurso 3 como "tipos relativamente estáveis de enunciados". Eles são heterogêneos, se diferenciam e se ampliam conforme a evolução de cada esfera da atividade humana, bem como se caracterizam por seu conteúdo temático, sua estrutura composicional e seu estilo. Numa perspectiva didática, tomando como base os estudos bakhtinianos, Schneuwly e Dolz (2004) afirmam ser os gêneros textuais megainstrumentos, que, ao entrarem na escola, tornam-se, ao mesmo tempo, instrumentos de comunicação e objetos de ensino e de aprendizagem.

Os autores asseguram também que, para se tornarem objetos de ensino, os gêneros textuais devem passar pelo processo de modelização didática condição necessária para haver ensino. Sobre isso, discorremos na próxima seção.

\section{0 processo de modelização didática}

De acordo com De Pietro e Schneuwly (2006) o processo de modelização envolve a construção de um modelo didático, que se materializa em sequências didáticas. Para os autores, um modelo didático põe em evidência as dimensões ensináveis de um objeto de conhecimento. Para que seja construído, é necessário considerar as práticas sociais de referência, a literatura sobre o gênero, as práticas linguageiras dos alunos e as práticas escolares. Na visão de De Pietro e Schneuwly (2006, p. 33),

[...] a modelização se constrói na interseção dessas quatro fontes de dados, dessas quatro determinações. É dessa forma que ela pode garantir, ao mesmo tempo, sua legitimidade - já que ela se apoia nas

\footnotetext{
3 Partimos da definição de Bakhtin (1997), mas adotamos o termo gênero textual, pois nos alinhamos às discussões sobre o ensino de gênero e o processo de modelização realizadas por Schneuwly e Dolz (2004). De acordo com estes autores, gêneros textuais são "textos com características semelhantes". Vale mencionar ainda que fazemos diferença entre tipo textual e gênero textual, sendo o primeiro um conjunto de "sequências linguísticas ou sequências de enunciados" (MARCUSCHI, 2005, p. 23).
} 
práticas sociais de referência e na literatura existente - e sua pertinência - já que ela também leva em consideração tanto as práticas, em desenvolvimento, dos alunos, quanto as práticas escolares.

A respeito do modelo didático, de acordo com os autores, ele precisa estar assentado em três princípios: princípio da legitimidade, princípio da pertinência e princípio da solidarização. O primeiro faz referência aos conhecimentos culturais ou oriundos de pesquisas; o segundo diz respeito às capacidades dos alunos, às finalidades e aos objetivos da escola; e o terceiro corresponde a tornar coerentes os conhecimentos de acordo com os objetivos pretendidos.

Schneuwly e Dolz (2004, p. 82) afirmam que: "1. Ele [modelo didático] constitui uma síntese com objetivo prático, destinada a orientar as intervenções dos professores; 2 . ele evidencia as dimensões ensináveis, com base nas quais diversas sequências didáticas podem ser concebidas.". Isto é, ele é um dispositivo essencial para definir o objeto a ser ensinado e suas dimensões.

A sequência didática consiste em "um conjunto de atividades escolares organizadas, de maneira sistemática, em torno de um gênero textual oral ou escrito." (NOVERRAZ; DOLZ; SCHNEUWLY, 2004, p. 84). Para os autores, essa ferramenta metodológica tem por finalidade ajudar os alunos a dominar um gênero textual, possibilitando assim o desenvolvimento das habilidades relacionadas à escrita e à oralidade. A sequência didática deve ser organizada da seguinte forma: apresentação da situação de comunicação, produção inicial, módulos e produção final. Na apresentação da situação de comunicação, é exposto aos alunos o projeto de comunicação a ser desenvolvido e se abordam informações sobre o conteúdo temático e à estrutura composicional do gênero em estudo. A primeira produção tem como função orientar as intervenções posteriores do professor e permitir aos alunos conscientizarem-se das dificuldades que apresentam na produção de um texto de um determinado gênero. Os módulos são constituídos de situações em que haverá o tratamento dos problemas que os estudantes apresentaram na primeira produção e o fornecimento de instrumentos que os auxiliem a resolvê-los. A produção final é 
o momento em que eles poderão pôr em prática os conhecimentos adquiridos ao longo dos módulos.

\section{Procedimentos Metodológicos}

Para a realização da pesquisa, adotamos a abordagem qualitativa (LÜDKE; ANDRÉ, 1986), pois buscamos compreender o fenômeno sem a necessidade de quantificá-lo. Quanto ao procedimento, recorremos à pesquisa documental (GODOY, 1995), uma vez que usamos como corpus de pesquisa materiais que não receberam "tratamento analítico" e que "[...] podem ser reelaborados de acordo com os objetivos da pesquisa." (PRODANOV; FREITAS, 2013, p. 55), isto é, nos valemos de notas de campo feitas por estagiárias e de sequências didáticas por elas elaboradas.

Da pesquisa, participaram uma escola da rede municipal e duas escolas estaduais, localizadas em bairros periféricos de Belém (Pará) - escolhidas mediante adesão dos professores titulares à investigação. No que diz respeito às estagiárias que ministraram as aulas, as três alunas eram do curso de Letras, da Universidade Federal do Pará (Campus Belém). Duas delas estavam participando do Programa de Iniciação Científica, e uma participava do grupo de pesquisa como voluntária. Neste artigo, as estagiárias são identificadas como E1, E2 e E3. E1 trabalhou com artigo de opinião, E2 com artigo enciclopédico e E3 com conto de terror. Apesar de não terem sido professoras, já haviam realizado oficinas de leitura em outras escolas e, na época, estavam cursando a disciplina Estágio Supervisionado no Ensino Fundamental. Cada uma delas ficou responsável por uma turma do $9^{\circ}$ do Ensino Fundamental. E1 atuou em uma turma com 17 alunos (T1), E2 em uma com 36 (T2), e E3 em uma com 35 (T3). Os 89 alunos participantes da pesquisa tinham entre 13 e 16 anos, sendo 40 meninos e 49 meninas; todos economicamente desfavorecidos. As aulas foram ministradas no horário da disciplina Língua Portuguesa, uma vez por semana, com duração de 2 horas-aula. Ao todo, houve 18 encontros: cinco na T1, seis na T2 e seis na T3. 
O corpus da pesquisa constitui-se de três sequências didáticas de leitura e de 36 horas-aula registradas em notas de campo; notas essas escritas pelas estagiárias. Cada sequência estava organizada em torno de um gênero textual, a saber: artigo de opinião (SD1), artigo enciclopédico (SD2) e conto de terror (SD3).

Com vistas à construção do corpus, considerando o pressuposto teóricometodológico do modelo de sequência didática elaborado por Noverraz, Dolz e Schneuwly (2004), aplicamos uma sequência cujo foco era a leitura ${ }^{4}$ e não a produção escrita e/ou oral. Para isso, partimos da ideia de promover um primeiro contato dos alunos com o gênero, com o objetivo de fornecer conhecimentos sobre ele, a fim de que os estudantes os acionassem durante a leitura de diferentes textos do gênero em foco. Tal como no modelo genebrino, incluímos momentos de avaliação, as quais foram baseadas no modelo Saeb, com o propósito de orientar as ações posteriores das estagiárias. A finalidade da primeira avaliação era promover um diagnóstico da turma e da última era verificar o que os alunos passaram ou não a dominar após a intervenção. Entre as avaliações, elaboramos etapas para ensinar estratégias de leitura, com o propósito de que os alunos desenvolvessem a compreensão global dos textos. As sequências didáticas de leitura construídas organizaram-se em:

- Introdução ao gênero: foco nas características do gênero (conteúdo temático, forma composicional, estilo, situação de comunicação).

- Atividade de avaliação 1: verificar as habilidades de leitura que os alunos dominavam ou não.

- Estratégias de leitura: focar em uma ou mais estratégias utilizadas antes da leitura, durante a leitura e/ou depois da leitura.

- Atividade de avaliação $2^{5}$ : verificar as habilidades de leitura que os alunos passaram a dominar ou não.

\footnotetext{
${ }^{4}$ Trata-se de um dispositivo didático que ainda está em desenvolvimento, então neste trabalho falamos de um modo geral sobre como organizamos a sequência de leitura.

${ }^{5}$ Neste artigo, não focamos o desempenho dos alunos, apenas descrevemos e analisamos as práticas de ensino das estagiárias, no que diz respeito ao ensino de estratégias de leitura.
} 
Para a produção das sequências, foram construídos previamente o modelo didático de cada um dos gêneros textuais selecionados e, posteriormente, foram elaboradas atividades que buscaram explorar algumas estratégias de leitura, a saber: predição, autointerrogação e sumarização, bem como saberes relacionados aos gêneros textuais estudados, com vistas ao desenvolvimento da compreensão leitora dos alunos. As estratégias foram selecionadas em função das etapas de processamento do textual, isto é: antes da leitura, durante a leitura e depois da leitura.

Nas sequências didáticas previamente produzidas, as tarefas de leitura foram organizadas em cinco etapas por E1 e E2 e em seis por E3. Cada estagiária desenvolveu seu próprio material, tomando como referência as discussões sobre gênero, modelo didático, sequência didática e estratégia de leitura - realizadas durante as reuniões do grupo de pesquisa - e orientando-se, para isso, pela organização geral da sequência proposta pela orientadora.

\section{Estratégias de leitura mobilizadas durante a realização da sequência}

Nas sequências didáticas planejadas, estava prevista a realização de diferentes estratégias de leitura para viabilizar a compreensão do texto. Algumas foram incluídas nas sequências didáticas elaboradas e foram ensinadas explicitamente, como predição, autointerrogação e sumarização; outras estavam previstas nos pressupostos teórico-metodológicos sob os quais a sequência didática de leitura tinha sido concebida, como definição de objetivos e ativação de conhecimentos prévios.

Nesta seção, descrevemos e analisamos o que foi efetivamente realizado em sala de aula pelas estagiárias e levantamos hipóteses sobre os fatores que podem ter influenciado determinadas ações no transcurso das aulas. 
Definição de objetivos de leitura

Por que a definição de objetivos é imprescindível no processo de compreensão de texto? Porque o olhar do leitor é dirigido por meio dos objetivos (ANTUNES, 2003; KOCH; ELIAS, 2014). Caso não haja clareza por qual motivo determinado texto será lido, o leitor não terá um caminho definido a percorrer e não poderá mobilizar estratégias que possam the auxiliar no processamento textual. Sobre isso, Solé (1998, p. 69, grifo nosso) afirma que as estratégias de leitura envolvem "[...] autodireção [...] e autocontrole, isto é, a supervisão e a avaliação do próprio comportamento em função dos objetivos que o guiam e da possibilidade de modificá-lo em caso de necessidade".

Sabendo que esse era um dos pressupostos da sequência didática de leitura, esperava-se que as estagiárias incentivassem a definição de objetivos pelos alunos. Ao contrário, percebemos que apenas uma delas fez menção à importância de definirmos objetivos, como vemos no trecho abaixo.

\begin{abstract}
Antes de iniciar a oficina, perguntei para os alunos por que lemos. Uns responderam que era para estudar. Perguntei o que ler. Não responderam. Perguntei para que ler. Também não responderam. Perguntei como eles faziam para escolher um livro. Perguntei o que chamava a atenção deles para que eles se interessassem em ler um livro. Alguns responderam que o modo como a capa é organizada desperta o interesse para a leitura. Tais perguntas tiveram por objetivo mostrar para o aluno uma motivação/finalidade para o ato de ler. Depois perguntei como que eles faziam as leituras das mensagens seja do WhatsApp, seja do Facebook. Perguntei se eles liam as mensagens que julgavam mais importantes, por exemplo, as mensagens dos pais, do melhor amigo etc. Ao fazer essas perguntas, tinha como objetivo saber como eles selecionavam as leituras. Uma aluna respondeu que silenciava as mensagens de grupos, não as lia, pois não achava interessante; os demais não responderam. Então expliquei que fazemos leituras motivados por algum objetivo, que pode ser: para aprender, se divertir, nos informar sobre algo etc. (Estagiária 1)
\end{abstract}

No trecho, observamos que E1 procurou mostrar aos alunos a importância de ter um objetivo para ler um texto e que selecionamos o que vamos ler conforme nossas finalidades de leitura. No entanto, ela não chegou a estimulálos a pensar por que leriam os textos "Assédio sexual: o ilícito silencioso" e 
"Violência sexual: marcas no corpo e na alma". Considerando as reflexões sobre o trabalho com definição de objetivos, advindos de pesquisas (KLEIMAN, 1992; SOLÉ, 1998), seria esperado que E1 propusesse objetivos explícitos aos alunos, por exemplo: ler para conhecer ou saber mais sobre um assunto; ler para identificar o posicionamento do autor; ler para apresentar as principais ideias discutidas no texto aos colegas; ler para se posicionar a favor ou contra a ideia defendida pelo autor etc., porque, por meio dessas ações, os estudantes poderiam ser orientados a selecionar estratégias adequadas para alcançar a finalidade proposta.

A condução desse momento da leitura, no entanto, pode não ter representado, segundo nossa análise, contribuição para a formação de um bom leitor, conforme descrito por Kleiman (1992, p. 76):

O leitor experiente tem duas características básicas que tornam a sua
leitura uma atividade consciente, reflexiva e intencional: primeiro, ele
lê porque tem algum objetivo em mente, isto é, sua leitura é realizada
sabendo para que está lendo, e, segundo, ele compreende o que lê, o
que seus olhos percebem seletivamente é interpretado, recorrendo a
diversos procedimentos para tornar o texto inteligível quando não
consegue compreender.

O foco na definição de objetivos para a leitura poderia ter estimulado os alunos a refletir sobre as estratégias necessárias à compreensão do texto. Por que eles iriam ler artigos de opinião sobre assédio? Por que eles iriam ler artigos enciclopédicos sobre profissão? Por que eles iriam ler contos de terror? Como as atividades propostas foram definidas apenas pelas estagiárias, talvez, eles tenham entendido se tratar de mais uma atividade de leitura escolar, isto é, ler o texto e responder a um questionário com perguntas de compreensão e interpretação.

Um trabalho mais específico sobre a estratégia de definição de objetivos permitiria aos alunos "[...] compreender os propósitos implícitos e explícitos da leitura. Equivaleria a responder às perguntas: Que tenho que ler? Por que/para que tenho que lê-lo?" (SOLÉ, 1998, p. 73). Ao fazerem isso, eles estariam realizando também a estratégia de monitoração, porque essa ocorre uma vez 
que o leitor tenha definido objetivos para sua leitura. Se soubessem, por exemplo, que leriam o conto de terror "Alma perturbada" para descobrir se o narrador-personagem tinha ou não irmão, isso provavelmente os teria motivado durante a leitura, e os alunos teriam um objetivo para alcançar: descobrir algo que não estava evidente no texto. Exigiria deles muito mais do que passar o olho pela página; teriam que construir inferências a partir das pistas linguísticas presentes no texto. Dessa forma, a atividade de leitura poderia ter sido muito mais desafiadora para eles. Como exemplificado, o objetivo não precisa ser complexo, basta orientar a leitura dos alunos. Em todo caso, nas notas de campo e nas sequências didáticas, não é possível observar orientações referentes ao por que ler os textos sugeridos. Então parte importante do trabalho com estratégia deixou de ser feito e não permitiu que os alunos acionassem outros procedimentos que poderiam ajudá-los no processamento textual. Uma primeira observação que podemos fazer aqui sobre a prática das estagiárias diz respeito à dificuldade de desenvolver na prática uma das estratégias estudadas na leitura do texto "O ensino de estratégias de compreensão leitora", de Isabel Solé.

\section{Ativação de conhecimento prévio antes da leitura}

Reconhecendo que a ativação de conhecimento prévio é importante para a compreensão do texto, as sequências didáticas foram planejadas de modo a prever momentos em que as estagiárias apresentariam textos ou vídeos com o objetivo de dar suporte aos alunos para a leitura do texto do gênero em estudo. Esse planejamento foi observado no trabalho realizado pelas três estagiárias. E1 fez uso de vídeos para introduzir o tema assédio, E2 recorreu a uma reportagem sobre uma festa que ridicularizava alguns tipos de trabalho para iniciar a discussão sobre profissão e E3 apresentou uma lenda urbana para estimular os alunos a pensar sobre os elementos que compõem histórias de terror. Todos esses movimentos foram feitos na etapa cujo objetivo era promover o primeiro contato dos alunos com o gênero e com a temática a ser discutida ao longo das aulas. 
E1, por exemplo, apresentou as letras das canções "Chega de Fiu-Fiu" e "Pagu", com vistas a não apenas ativar os conhecimentos prévios dos alunos sobre assédio, como também fornecer conhecimentos que, talvez, eles não tivessem, como observamos no trecho da nota de campo a seguir. Esse movimento didático contribuiu para que os estudantes, ao ler os artigos de opinião propostos, fizessem associação com as letras de canção, aprofundando a compreensão deles dos textos.

Exibi primeiro o vídeo da cantora Paula Lima, a música "Chega de Fiufiu", e em seguida o videoclipe da cantora Rita Lee, a música "Pagu". Após a exibição dos videoclipes, perguntei para a turma sobre o que os vídeos falavam. Um aluno comentou que: "falava sobre a questão de os homens ficarem 'mexendo' com a mulher na rua." Tal comentário foi sobre o vídeo da cantora Paula Lima. Outro comentou que "falava sobre a objetificação da mulher, pois na música a cantora falava que o peito dela não era de silicone, que nem toda brasileira era só bunda.". (Estagiária 1)

Ao fazer isso, E1 preparou os alunos para a leitura do texto "Assédio sexual: o silêncio não é uma opção", favorecendo que eles agregassem o que fora discutido em sala ao conhecimento enciclopédico (KOCH; ELIAS, 2014). Eles, assim, ao ler o texto, poderiam ativar os seus conhecimentos de mundo e os relacionar com o texto lido, viabilizando a compreensão do assunto abordado.

$E 2$, para ativar os conhecimentos dos alunos sobre profissão, apresentou uma reportagem sobre alguns tipos de trabalho pouco valorizados pela sociedade brasileira, como vemos neste recorte da nota de campo.

[...] disse que o tema dos artigos enciclopédicos era profissões e perguntei aos alunos quais eram as profissões dos pais, se eles sabiam o motivo da escolha da profissão e quais profissões eles queriam seguir. A maioria dos alunos gostaria de seguir a profissão de médico, advogado e policial. Já em relação às profissões dos pais, a maioria trabalhava em lojas, eram servidores públicos ou autônomos.

Após esse momento, entreguei uma reportagem a todos os alunos sobre uma festa intitulada "Se nada der certo", feita por uma escola com o objetivo de brincar com as profissões que os alunos teriam que seguir caso não conseguissem passar no vestibular. (Estagiária 2) 
Ela buscou, assim, incentivá-los a pensar sobre as diferentes profissões que existem e a ativar o que sabiam sobre cada uma, para promover compartilhamento e ampliação de repertório.

Ao promover a troca de informações, E1 e E2 permitiram que os alunos aprendessem entre si, uma vez que, nas interações orais, os conhecimentos podem ser obtidos ou atualizados. A mobilização e ampliação de conhecimentos prévios podem ser feitas de diferentes formas, como:

Dar explicação geral sobre o que será lido. Não se trata tanto de explicar o conteúdo, mas de indicar sua temática aos alunos, para que possam relacioná-la a aspectos da sua experiência prévia. [...] Incentivar os alunos a exporem o que já sabem sobre o tema. (SOLÉ, 1998, p. 105-106)

Observamos que E1 usou músicas para aproximar os alunos do tema. Já E2, anunciou o tema, solicitando a participação dos estudantes, mas não explorou o texto sobre as profissões. Vale mencionar que a reportagem sobre a festa das profissões ("Dia do 'se nada dar certo' acende debate sobre meritocracia e privilégio") promovia uma reflexão sobre a importância de cada profissão e o respeito que se deve ter para com cada uma. Embora tal abordagem seja interessante, não necessariamente os preparou para a leitura do artigo enciclopédico "Trabalho", que abordava os tipos de trabalho em diferentes sociedades. É preciso, então, no momento da seleção dos textos e de atividades, considerar se o que foi selecionado pode contribuir, de fato, à compreensão, visto que quanto mais conhecimento prévio sobre o assunto mais acessível será o texto para o leitor.

E3 também estimulou que os alunos falassem sobre as histórias de terror que conheciam, conforme mostra o trecho da nota de campo a seguir. Isso favoreceu que acionassem os conhecimentos prévios que tinham e compartilhassem com os colegas o que sabiam, sendo uma situação favorável para a composição de novos conhecimentos e para a criação de um ambiente favorável à leitura dos textos. 
[...] perguntei se eles gostavam de histórias de terror, então pude perceber que eles começaram a achar interessante aquela conversa, citaram algumas histórias que já haviam escutado algumas muito comuns aqui em Belém. Perguntei também se já tinham lido em livros ou se já tiveram contato com elas na internet, poucos disseram que faziam pesquisa na internet a respeito desses textos, mencionaram também que gostavam muito de filmes de terror. A maioria, contudo, só escutava histórias de terror quando alguém contava para eles. [...] Os alunos participaram bastante desse momento, comentaram que seus parentes mais velhos contavam lendas sobre a Matinta Pereira, sobre o Curupira. Eles contaram aquilo que tinham ouvido ao longo da vida e mostrando seus conhecimentos prévios sobre o assunto. (Estagiária 3)

Por meio do relato de E3, percebemos que o movimento de ativação de conhecimento prévio é importante não apenas para engajar os alunos na atividade de leitura, mas também para ajudá-los a realizar predições sobre o texto. Segundo Kleiman (1992, p. 77), "[...] o leitor proficiente faz escolhas baseando-se em predições quanto ao conteúdo do livro. Essas predições estão apoiadas no conhecimento prévio [...]". Por isso, auxiliá-los a pensar sobre o que eles sabem sobre o tema é fundamental antes da leitura.

Como vimos nos três exemplos acima, todas as estagiárias usaram algum procedimento para incentivar os alunos a compartilhar o que já sabiam sobre o tema, criando um repertório comum à turma e, ao mesmo tempo, favorecendo que recuperassem as informações compartilhadas durante a leitura do texto. Vale mencionar que as atitudes delas foram conscientes, porque já haviam definido previamente na sequência didática que determinadas ações seriam desenvolvidas, o que ajudou sua realização em sala de aula.

É importante salientar que a primeira etapa da sequência foi construída com a finalidade de permitir aos alunos construir ou aprofundar conhecimentos sobre o gênero em estudo. Nos relatos das estagiárias, contudo, não percebemos os conhecimentos sobre o gênero sendo mobilizados nas atividades propostas, embora elas tenham dito acesso aos estudos sobre o gênero como megainstrumento que serve de suporte para as atividades de linguagem nas diferentes situações de comunicação (SCHNEUWLY; DOLZ, 2004).

De acordo com os registros das aulas, apenas na etapa 1 ocorre referência direta aos saberes relacionados ao gênero, como exemplificado a seguir. 
Quando perguntei se eles sabiam o que era opinião, responderam que "era quando a pessoa expressa sobre um assunto; era falar o que ela pensa sobre algo.". Com base nisso, expliquei que o texto era do artigo de opinião [...] A partir do texto lido, expliquei as principais características do gênero, tentando fazê-los compreender as características do gênero artigo de opinião, por meio de perguntas. Perguntei se eles sabiam onde esses textos eram publicados, eles não souberam responder; então expliquei que eles pertenciam à esfera jornalística e que poderiam ser publicados em jornais e revistas impressos ou virtuais. Em aula expositiva, expliquei que o autor do artigo de opinião tem por finalidade convencer o leitor de sua ideia através da discussão de temas polêmicos. (Estagiária 1)

Com exceção de E3 que retoma a diferença entre lenda urbana e conto de terror antes de os alunos fazerem a avaliação 1 (etapa 2), as demais não chegaram a retomar explicitamente as finalidades e características do gênero. Como evidenciam as notas de campo e a forma como a sequência foi elaborada (isto é, dedicando fases para trabalhar uma estratégia de cada vez), nenhuma estimulou os alunos a retomar o que sabiam sobre artigo de opinião, artigo enciclopédico ou conto de terror na realização das atividades, por exemplo, de predição, de autointerrogação e de sumarização.

Na SD 1, há atividades de identificação do ponto de vista do autor e dos argumentos que o sustentam, aspectos esses relacionados à forma de organização do artigo de opinião. Mas, isso não aparece associado às atividades sobre antecipação que consta na mesma etapa. Como as atividades não foram corrigidas e as respostas não foram discutidas com os alunos, a associação que poderia ser feita entre os saberes sobre o gênero (conhecimento prévio) e a estratégia em foco deixou de ser realizada, dificultando assim que eles articulassem os diferentes procedimentos envolvidos na construção de sentidos do texto. Quando questionada sobre por que não ter corrigido os exercícios com os alunos, E1 disse não ter tido tempo suficiente, porque eles demoravam a se acalmar para a aula começar. Isso levanta uma questão sobre a não percepção de que a correção das atividades é fundamental para a aprendizagem. Parece que E1, por não dispor de muitas horas-aula, buscou usar toda a sequência, o que nos faz relembrar o que muitos professores dizem quando questionados sobre a realização de algumas atividades: "não temos tempo, precisamos cumprir 
o programa". No caso explicitado, o programa parece ser a sequência didática previamente elaborada. Mas, surge o seguinte questionamento: como proporcionar a aprendizagem se não houver tempo para trabalhar as dificuldades dos alunos, que certamente seriam reveladas na realização das atividades propostas?

\section{Predição}

Apresentar aos alunos estratégias de leitura é fundamental para o desenvolvimento da compreensão leitora. Observamos que, ao explicitá-las, as estagiárias ajudaram os alunos a perceber que eles podem usar estratégias para melhor compreender um texto.

Para ensinar a predição, por exemplo, E3 fez uso da capa, do título do livro, das informações sobre o autor e do sumário para levar os estudantes a levantar hipóteses sobre o conteúdo dos livros.

[...] Neste dia, levei três livros de contos de terror para a sala de aula, os quais foram usados para compor a atividade do dia. [...] comecei a explicar a importância das estratégias que estudaríamos, pontuei que durante a prática de leitura encontramos dificuldades no caminho, mas que poderíamos usar algumas estratégias para tentar resolvê-las. [...] Comecei a apresentar os livros que trouxe para a aula, entreguei-os aos alunos e pedi para que olhassem bem o nome do autor, a capa, 0 sumário, as informações sobre o autor e o próprio título dos textos dentro dos livros.

[...] Após a análise de cada um dos livros, questionei-os sobre o tema de cada um, eles responderam que eram livros de terror, então perguntei o porquê daquela resposta, e alguns deles responderam que era por causa da capa, em que havia imagens assustadoras, que causavam medo. Perguntei também sobre o autor, se alguém já tinha ouvido falar daqueles autores; todos disseram que não, mencionei que aqueles eram escritores consagrados do gênero conto de terror. [...] depois expliquei que esse momento de análise é muito importante para o leitor, pois através das informações presente nos livros ele poderia prever qual seria o conteúdo do texto sem antes lê-lo, disse que aquela era uma das estratégias usadas na leitura. (Estagiária 3)

Ao ensinar explicitamente a estratégia, ela pôde contribuir para que eles tomassem consciência de ações que leitores fluentes fazem. 
E1 também usou a estratégia de levantamento de hipóteses, mas, para isso, usou o título do artigo, como vemos no relato a seguir.

[...] para desenvolver o assunto precisei projetar no quadro o título do texto: "Assédio sexual: resquício da cultura machista". [...] Apresentado o título, perguntei aos alunos sobre qual assunto marcado no título. Responderam "sobre assédio sexual". Perguntei se era só isso. Responderam "sobre o machismo". Perguntei de que assunto o texto aborda tomando o título "Assédio sexual: resquício da cultura machista" como referência. Não responderam. Perguntei se eles sabiam o que era hipótese, e eles responderam que não. Então, expliquei que hipótese era "supor" sobre algo, "achar que", e que na leitura do título podemos levantar hipóteses sobre o que vai ser falado no texto. (Estagiária 1)

Nesse caso, a estagiária poderia ter formulado outras perguntas para ajudar os alunos a fazer predições sobre o texto. Ao responder assédio para a pergunta sobre o assunto, eles apenas reproduziram o que estava no título "Assédio sexual: resquício da cultura machista". Talvez, se ela os tivesse estimulado a pensar em exemplos de assédio, em como as pessoas reagem a situações dessa natureza, sobre que posicionamento o autor assumiria no texto etc., eles teriam conseguido acionar seus conhecimentos de mundo para fazer as predições. Conforme Kleiman (1992, p. 79) pontua,

[...] é possível criar condições para o aluno fazer predições, orientado pelo professor, que além de permitir-lhe utilizar seu próprio conhecimento, supre eventuais problemas de leitura do aluno, construindo suportes para o enriquecimento dessas predições e mobilizando seu maior conhecimento sobre o assunto.

Em relação à E1, observamos também sua preocupação em esclarecer o que era hipótese, priorizando assim um conhecimento conceitual sobre a estratégia. Embora compreensível em uma situação de ensino, o foco da proposta era levar os alunos a adquirir um saber procedimental, então a apresentação de outros exemplos poderia ter demonstrado melhor o que se esperava que fizessem a partir da leitura do título. Podemos dizer que a força da tradição escolar prevaleceu por parte das estagiárias quando os estudantes apresentaram dúvidas. Possivelmente, por falta de experiência, a conceituação tenha sido, a 
opção mais adequada. Na mesma direção da conceituação, seguiu E2, a qual também apresentou uma explicação genérica sobre estratégias de antecipação.

As notas de campo nos permitiram verificar que houve o incentivo ao levantamento de hipóteses pelos alunos, mas, para isso, foi usado apenas o que estava linguisticamente posto no título ou na capa. As estagiárias poderiam do mesmo modo tê-los levado a recuperar conhecimentos sobre o gênero e conhecimentos prévios para fazer predições. Um trabalho dessa natureza poderia contribuir para a formação de um leitor proficiente, o qual, nas palavras de Kleiman (1992, p. 77), "[...] faz escolhas baseando-se em predições [...] [que] estão apoiadas no conhecimento prévio, tanto sobre o assunto (conhecimento enciclopédico), como sobre o autor, a época da obra (conhecimento social, cultural e pragmático), o gênero (conhecimento textual)".

Vale ressaltar também que, nas notas de campo, não consta que, após a leitura dos textos, as estagiárias tenham proporcionado a checagem das hipóteses - algo extremamente importante no processamento do texto. Encontramos, todavia, nas SD 1 e 2, atividades que levavam os alunos a checar as hipóteses.

2. Suas hipóteses se confirmaram? Justifique sua resposta. (Sequência didática 1)

4) Agora, leia os textos 1 e 2, publicados na plataforma de aprendizagem online Britannica ${ }^{\circledR}$ Escola para os alunos do Ensino Fundamental, e verifique se o que você pensou sobre o conteúdo do texto se confirmou ou não. (Sequência didática 2)

Como não houve correção coletiva das atividades, apenas a individual, e como não tivemos acesso ao material dos alunos, porque foi devolvido, não é possível saber se conseguiram levantar e confirmar ou não as hipóteses. Essas informações seriam necessárias para perceber se foram capazes de exercer controle consciente sobre a compreensão e a regulação desse processo. Podemos apenas constatar que havia essa preocupação no plano e na sequência usada em sala de aula. Não há, entretanto, registro de intervenções das estagiárias quando as hipóteses levantadas pelos alunos divergiam, por exemplo, do conteúdo do 
texto. Ao não estimular a verificação de hipóteses, elas deixaram de executar uma parte importante do trabalho com as estratégias, que é permitir aos alunos pensar em outros procedimentos quando percebem que o selecionado não trouxe os resultados esperados. De acordo com Menegassi (2010, p. 44),

[...] essas antecipações podem ser comprovadas ou não. Ao serem comprovadas, o leitor sente maior segurança nas estratégias que escolheu, dando prosseguimento à conduta iniciada, pois está no caminho certo. Por outro lado, ao ter suas predições não comprovadas, ele é obrigado a rever seu procedimento, reavaliando o uso das estratégias, readequando-as ou, até mesmo, trocando de estratégia, escolhendo uma que lhe possibilite uma antecipação mais eficiente.

Algumas ações poderiam ter sido realizadas para favorecer a conscientização dos alunos sobre o levantamento e a confirmação de hipóteses, o que, por conseguinte, poderia tê-los levado a adotar um comportamento semelhante em outras situações de ensino, transformando-os em leitores ativos que participam da construção de sentidos do texto com base em seus objetivos, nos conhecimentos prévios, no conhecimento linguístico e no conhecimento interacional (KOCH; ELIAS, 2014). Já que a compreensão não é construída apenas com a decodificação, é necessário haver a articulação entre esses diferentes conhecimentos.

Além disso, a explicitação do que levou à determinada antecipação é um pré-requisito para os alunos compreenderem como mobilizar adequadamente as pistas linguísticas e o conhecimento prévio na atividade de leitura. Não basta lhes dizer para levantar e confirmar hipóteses, é necessário fazê-los dizer o que usaram para realização dessas ações, porquanto é apenas compreendendo o seu processo mental que o professor ou o estagiário pode reformular e adequar suas instruções para promover a aprendizagem.

Muitas das predições que os leitores proficientes fazem ocorrem durante a leitura do texto. Na medida em que leem o texto, percebem o que corresponde ou não, mudando assim suas predições. Esse movimento, infelizmente, parece não ter sido realizado, o que diminuiu as chances de os alunos perceberem como procedemos em situações de leitura, não apenas no ambiente escolar, mas 
também em outras situações de comunicação. Perdeu-se de vista que a leitura consiste em "[...] um processo de emissão e verificação de previsões que levam à construção da compreensão do texto" (SOLÉ, 1998, p. 115).

\section{Autointerrogação}

Segundo Solé (1998), a formulação de perguntas sobre o texto pode auxiliar os alunos na compreensão, uma vez que pode ajudá-los a centrar a atenção em questões fundamentais, conforme os objetivos de leitura. Seguindo esse pressuposto, as três estagiárias buscaram ensinar a estratégia de autointerrogação de forma explícita ou não.

[...] Li com a turma, primeiramente, o texto "O gato preto" $e$, ao longo da leitura, orientei os alunos a pensar nas perguntas norteadoras depois de cada parágrafo. Líamos um trecho e então fazíamos uma pausa para pensarmos numa pergunta para o que havia sido lido. Eu li a primeira página e, após cada parágrafo lido, fazia uma pausa e pedia para que eles pensassem em alguma pergunta que fosse respondida pelo trecho que nós tínhamos acabado de ler. No primeiro parágrafo, eles não conseguiram pensar numa pergunta, então voltei ao texto lendo novamente o parágrafo e criei uma pergunta como um exemplo do que deveriam fazer. Após a leitura do primeiro parágrafo, sugeri que a pergunta fosse a seguinte: "O que o personagem iria relatar?". Expliquei que a pergunta era respondida pelo parágrafo em questão e que sempre deveríamos pensar em perguntas que seriam respondidas pelo parágrafo lido. Depois, continuei a leitura, parando após cada parágrafo para elaborarmos uma pergunta de acordo com o trecho lido. (Estagiária 3)

E3 ensinou diretamente a estratégia, apresentando aos alunos a pergunta que poderia resumir adequadamente o conteúdo do parágrafo. Ao fazer isso, ela estimulou que assumissem uma postura ativa e relessem o texto buscando compreendê-lo melhor. A atitude dela também favoreceu que aqueles com mais dificuldade pudessem construir a compreensão durante a interação.

E1, por sua vez, apenas mencionou que a elaboração de perguntas pode ajudar na construção de resumos, porém não chegou a propor atividades para os alunos aprenderem a utilizar a estratégia de autointerrogação ou demonstrar como poderiam fazer perguntas ao texto. 
Mencionei também que podemos destacar partes do texto que apresentam as ideias principais do autor, que podemos fazer perguntas ao texto e com isso podemos fazer um resumo. Destaquei que tudo isso favorece para uma melhor compreensão. (Estagiária 1)

Com base nesse episódio, podemos dizer que faltou demonstrar como se elaboram perguntas para ajudar no monitoramento da compreensão. Por meio das explicações fornecidas, parece pressuposto que apenas a menção à estratégia levaria os alunos a adotar tal comportamento. Sabemos, contudo, que o ato de ler envolve tanto o domínio de saberes conceituais quanto procedimentais.

Já E2, apesar de fornecer explicações aos alunos após não conseguirem realizar a atividade proposta, pressupôs que conseguiriam construir perguntas sem que demonstrasse como fazê-lo.

Iniciei a aula retomando a estratégia anterior e disse que eles
aprenderiam outra estratégia, a estratégia durante a leitura. Entreguei
atividade e logo os alunos apresentaram dúvidas em como fazer
perguntas que retomassem informações no texto. Pedi para eles
olharem o primeiro texto, que trazia perguntas entre os parágrafos.
Percebendo que eles continuavam sem entender o que era para ser
feito, expliquei que, se eles precisassem ler uma bula de remédio, eles
precisariam se perguntar qual o efeito, para quem éindicado o remédio,
qual a dosagem máxima, o que acontece se tomar mais do que deveria.
Pedi que lessem novamente o texto e se questionassem sobre que
informações no texto eram importantes para serem retomadas depois.
Após esse momento, a maioria conseguiu realizar a atividade.
(Estagiária 2)

É possível perceber que ela distribuiu o material sem explorar a primeira parte com os alunos; parte essa em que havia um texto, com perguntas entre os parágrafos, seguido de algumas atividades. Tal atitude mostra uma prática bastante recorrente em aulas de Língua Portuguesa: solicitar aos alunos que façam as atividades do livro didático sem que haja uma discussão prévia sobre o conteúdo ou a apresentação de explicações e modelos. Não consta nas notas de campo se ela buscou evidenciar o porquê de as perguntas terem sido criadas e que ao respondê-las eles teriam uma visão global do texto. Também não há menção acerca do modo como foi feita a correção das atividades. 
Considerando os relatos de E1 e E2, é possível afirmar que tal estratégia não foi diretamente ensinada ou por falta de conhecimento em instrução (como ensiná-la), ou por reprodução de práticas assimiladas anteriormente, durante o tempo em que elas foram estudantes.

Caso tivesse sido feito de forma efetiva, o trabalho com essa estratégia possivelmente teria contribuído para ajudar os alunos a lidar com dúvidas e com problemas de compreensão, a construir a interpretação do texto, bem como a saber o que fazer na fase da leitura que exige maior esforço do leitor: a leitura em si. Estimulá-los a se autoquestionar poderia auxiliá-los "[...] a formular perguntas pertinentes para o texto em questão." (SOLÉ, 1998, p. 119), o que, por conseguinte, poderia esclarecer dúvidas quanto ao entendimento do texto.

Sobre essa estratégia, vale mencionar que as atividades de leitura compartilhada poderiam favorecer que os alunos tomassem consciência dos movimentos que podem fazer durante a leitura. De acordo com Solé (1998, p. 121), eles só vão compreender e aprender a usar as estratégias por meio de "[...] tarefas de leitura compartilhada, nas quais o leitor vai assumindo progressivamente a responsabilidade e o controle de seu processo."

Considerando os registros das aulas, com exceção de E3, que leu o texto com os alunos e, com eles, elaborou perguntas sobre o texto em questão, as outras estagiárias não só não ofereceram um modelo como também não permitiram que, por meio da leitura compartilhada, pudessem se apropriar de uma estratégia que favorecesse o monitoramento da compreensão. Considerando os estudos sobre estratégias de leitura, seria necessário que E1 e E2 lessem o texto, elaborassem perguntas e estimulassem os alunos a fazer 0 mesmo. Assim eles poderiam aprender a usar a estratégia, uma vez que teriam um modelo e, ao mesmo tempo, seriam levados a fazê-lo, isto é, a se autoquestionar. Segundo Solé (1998, p. 120), "o importante é entender que, para dominar as estratégias responsáveis pela compreensão - antecipação, verificação, autoquestionamento [...] - não é suficiente explicá-las; é preciso colocá-las em prática, compreendendo sua utilidade". 


\title{
Sumarização
}

As atividades de resumo foram bastante recorrentes nas sequências didáticas elaboradas pelas estagiárias e tinham o objetivo de facilitar a compreensão global do texto. No entanto, a elaboração de sínteses foi apenas mencionada por E1 e E3, então possivelmente não foi ensinado aos alunos como resumir textos. Por exemplo, E3 em sua nota de campo mencionou cinco vezes que Ihes foi solicitado construir resumos, mas não identificamos explicações que orientassem essa construção.

\begin{abstract}
E fizemos essa análise das perguntas e dos parágrafos em todo o texto, e para finalizar pedi que dois alunos dessem sua resposta para a questão dois que pedia para que resumissem o texto "O casarão malassombrado", sempre observando as perguntas elaboradas. (Estagiária 3 , grifo nosso)
\end{abstract}

Percebemos assim que os alunos resumiram os textos, mas não foram instruídos sobre como fazer. A reflexão sobre o que era ideia principal e secundária nos textos seria necessária para que eles construíssem os resumos. Isso poderia tê-los levado a selecionar e destacar as informações mais importantes e não apenas sintetizar sem um critério definido para tal.

E1 menciona que destacar as ideias principais do autor pode ajudar a construção dos resumos, mas não chega a trabalhar com os alunos a identificação dessas ideias.

"Mencionei também que podemos destacar partes do texto que apresentam as ideias principais do autor, que podemos fazer perguntas ao texto e com isso podemos fazer um resumo". (Estagiária 1)

A leitura do texto e a identificação das principais informações com os alunos poderiam ter exemplificado o que ela Ihes mencionou. Infelizmente, isso não chegou a ser feito, então eles provavelmente, ao fazerem os resumos, utilizaram aquilo que já sabiam sobre e, conforme os relatos das aulas evidenciam, em geral, resumo era entendido como cópia de trechos do texto. 
Quanto à E2, não constam nas notas de campo referências à produção do resumo, embora na SD2, distribuída aos alunos, haja quatro atividades que preveem o resumo do texto lido em diferentes etapas. Segue um exemplo:

3) "Agora faça um breve resumo COM SUAS PALAVRAS sobre o artigo enciclopédico "Direito"." (Sequência didática 2, grifo da autora)

O fato de não haver instrução clara sobre a construção de resumos resultou em dificuldade para sintetizar os textos. As propostas parecem ter tido como objetivo verificar se os alunos compreenderam o texto. Não se considerou, no entanto, que tal atividade não é intuitiva, mas que demanda uma série de procedimentos, como identificar a ideia principal, diferenciar ideia principal de secundária e relacionar as informações conforme a intenção do autor. Segundo Solé (1998, p. 147), deve-se, por exemplo,

- Ensinar a encontrar o tema do parágrafo e a identificar a informação trivial para deixá-la de lado.

- Ensinar a deixar de lado a informação repetida.

- Ensinar a determinar como se agrupam as ideias no parágrafo para encontrar formas de englobá-las.

- Ensinar a identificar uma frase-resumo do parágrafo ou a elaborá-la.

Sabemos que não basta apenas solicitar a construção de um resumo. Os alunos precisam de instruções claras para aprender a elaborar texto desse gênero que evidenciem sua compreensão do material lido. A estratégia de produção de síntese deve ser desenvolvida de modo que eles entendam o que é um resumo, por que precisam resumir e em função de quais objetivos.

\section{Considerações Finais}

Neste artigo, apresentamos uma reflexão sobre o ensino de estratégias de leitura, com base na observação de três sequências didáticas orientadas por gênero, desenvolvidas em turmas do $9^{\circ}$ ano do Ensino Fundamental II. Conforme 
mencionado, para realizar a pesquisa, apoiamo-nos nos estudos sobre estratégias de leitura e modelização didática, os quais nos guiaram na construção de modelos e sequências didáticas e na análise dos dados construídos ao longo de 32 horasaula.

Como procedimento metodológico, recorremos às pesquisas qualitativa e documental, a fim de alcançar o nosso objetivo geral de pesquisa: demonstrar se houve o ensino de estratégias de leitura aos estudantes e de que maneira tais estratégias foram ensinadas.

No que diz respeito à primeira pergunta de pesquisa (De que forma a sequência didática planejada possibilitou ensinar sistematicamente as estratégias de leitura?), constatamos que a forma como a sequência didática de leitura foi organizada possibilitou o ensino de estratégias, embora em alguns momentos tenham faltado instruções mais claras para que os alunos construíssem um saber sobre e se apropriassem dos procedimentos ensinados. Ainda que as estagiárias tenham lido textos sobre estratégias de leitura e sobre modelização didática, a força da tradição escolar prevaleceu, principalmente, quando os alunos apresentaram dúvidas. Ao serem questionadas sobre a atividade proposta, as estagiárias frequentemente forneciam como explicação o conceito de estratégias. Possivelmente, por falta de experiência em mobilizar estratégias de leitura com os alunos, a conceituação tenha sido, para elas, a opção mais adequada. Parece que nem a orientação da importância de estimular os alunos a assumir uma postura mais ativa, nem o conhecimento teórico sobre estratégia foram capazes de sobrepor uma prática de ensino já adquirida, isto é, uma prática centrada na conceituação de termos.

A respeito da segunda pergunta de pesquisa (Como os conhecimentos relacionados às estratégias foram mobilizados pelas estagiárias no desenvolvimento da sequência didática?), com base na descrição e análise das notas de campo, observamos que as estagiárias mobilizaram diferentes conhecimentos sobre estratégia em seu fazer docente. Entre eles, podemos mencionar os seguintes: lemos de forma diferente de acordo com o nosso objetivo; antes de ler um texto é importante acionar o que já sabemos sobre o 
tema e o gênero textual; elaborar perguntas durante a leitura do texto pode nos ajudar a monitorar a nossa compreensão; e resumir um texto demonstra que entendemos o que lemos. Contudo, como dito anteriormente, faltaram instruções mais claras de compreensão leitora. Como visto, as estagiárias promoveram o levantamento de hipóteses, mas não elaboraram perguntas que permitissem aos alunos verificá-las após as leituras. Ao acionar essa estratégia, elas poderiam ter retomado a finalidade do gênero e o leitor previsto, bem como poderiam ter estimulado os alunos a antecipar, no caso do artigo de opinião, os argumentos que $o$ autor poderia apresentar e o ponto de vista defendido por ele com base nas informações, por exemplo, sobre seu papel social. A mobilização dessas estratégias possibilitaria um jogo de relações entre os diferentes conhecimentos, e a atividade não ficaria restrita à leitura de palavras do título. As estagiárias, uma vez tendo domínio de como fomentar a elaboração de hipóteses, poderiam servir de orientadoras para as predições dos alunos, fornecendo a eles pistas que os auxiliariam nesse processo, permitindo que se tornassem autoconfiantes no uso das estratégias para resolver possíveis dificuldades de leitura.

Em relação ao conhecimento pedagógico mobilizado, ao ensinar as estratégias, as estagiárias raramente apresentavam exemplos claros de como fazer, deixando os alunos tentarem descobrir o que poderiam fazer em cada situação proposta. Vimos que, diante da dificuldade, muitos desistiam de fazer a atividade. Se elas tivessem apresentado mais exemplos, se tivessem apresentado modelos, provavelmente, eles ter-se-iam desenvolvido mais em compreensão leitora durante as intervenções propostas.

A ausência frequente de modelos pode ter sido em decorrência da não apropriação pelas estagiárias de como ocorre a aprendizagem da leitura. Ainda que a concepção de leitura em que elas estavam fundamentadas fosse a interativa, esta não anula os processos internos (cognitivos) envolvidos no processamento textual. Parece então que as estagiárias conheciam as estratégias e sabiam que era importante promover a discussão dos textos, mas desconheciam os processos sobre como podemos viabilizar a aprendizagem de leitura e questões relacionadas à instrução. 


\section{Referências}

ANTUNES, Irandé. Aula de português. encontro e interação. São Paulo: Parábola, 2003.

BAKHTIN, Mikhail. Os gêneros do discurso: problemática e definição. In: BAKHTIN, Mikhail. A estética da criação verbal. São Paulo: Martins Fontes, 1997. p. 277-236.

BRASIL. Ministério da Educação. Base nacional comum curricular. educação é a base. Brasília: MEC, 2017.

DE PIETRO, Jean-François; SCHNEUWLY, Bernard. O modelo didático do gênero: um conceito da engenharia didática. Revista Moara, Belém, n. 26, p.1552, ago./dez. 2006.

DUKE, Nell K.; PEARSON, P. David. Effective practices for developing reading comprehension. In: FARSTRUP, Alan E.; SAMUELS, S. Jay. What research has to say about reading instruction. 3. ed. Newark, DE: International Reading Association, 2002. p. 208-242.

GODOY, A. S. Pesquisa qualitativa: tipos fundamentais. Revista de Administração de Empresas, São Paulo, v. 35, n. 3, p. 20-29, 1995. Disponível em: http://www.scielo.br/scielo.php?script=sci_arttext\&pid=S003475901995000300004. Acesso em: 29 out. 2019.

INEP - Instituto Nacional de Estudos e Pesquisas Educacionais Anísio Teixeira. Sistema de Avaliação da Educação Básica. Resultados do Saeb 2017. Brasília: MEC, 2017. Disponível em: http://portal.inep.gov.br/educacao-basica/saeb. Acesso em: 31 out. 2019.

KLEIMAN, Ângela. Texto e leitor: aspectos cognitivos da leitura. Campinas: Pontes, 1992.

$\mathrm{KOCH}$, Ingedore Villaça; ELIAS, Vanda Maria. Ler e compreender os sentidos do texto. São Paulo: Contexto, 2014.

LÜDKE, Menga; ANDRÉ, Marly Eliza Dalmazo Afonso de. Pesquisa em Educação: abordagens qualitativas. São Paulo: EPU, 1986.

MARCUSCHI, Luiz Antônio. Gêneros textuais: definição e funcionalidade. In: DIONISIO, Ângela Paiva; MACHADO, Anna Rachel Machado; BEZERRA, Maria Auxiliadora (org.). Gêneros textuais e ensino. 4. ed. Rio de Janeiro: Lucerna, 2005. p. 19-36.

MENEGASSI, Renilson José. Leitura e ensino. 2. ed. Maringá: Universidade Estadual de Maringá, 2010. 
NOVERRAZ, Michèle; DOLZ, Joaquim; SCHNEUWLY, Bernard. Sequências didáticas para o oral e a escrita: apresentação de um procedimento. In: SCHNEUWLY, Bernard; DOLZ, Joaquim. Gêneros orais e escritos na escola. Tradução e organização de Roxane Helena Rodrigues Rojo e Glaís Sales Cordeiro. Campinas: Mercado de Letras, 2004. p. 95-128.

PRODANOV, Cleber Cristiano; FREITAS, Ernani Cesar. Metodologia do trabalho científico: métodos e técnicas da pesquisa e do trabalho acadêmico. 2. ed. Novo Hamburgo: Feevale, 2013.

SCHNEUWLY, Bernard; DOLZ, Joaquim. Gêneros orais e escritos na escola. Tradução e organização de Roxane Helena Rodrigues Rojo e Glaís Sales Cordeiro. Campinas: Mercado de Letras, 2004.

SOLÉ, Isabel. Estratégias de leitura. 6. ed. Porto Alegre: Artmed, 1998. 